\title{
Is breech still being delivered vaginally? A comparative study
}

\author{
Saira Dars $^{1 *}$, Safia Malik ${ }^{1}$, Aijaz Bhurgri ${ }^{2}$ \\ ${ }^{1}$ Department of Obstetrics \& Gynaecology, Liaquat University Hospital, Sindh, Pakistan \\ ${ }^{2}$ Department of Radiology, Isra University Hospital, Hyderabad, Sindh, Pakistan
}

Received: 9 January 2014

Accepted: 2 February 2014

*Correspondence:

Dr. Saira Dars,

E-mail: saira_dr01@yahoo.com

(C) 2014 Dars S et al. This is an open-access article distributed under the terms of the Creative Commons Attribution Non-Commercial License, which permits unrestricted non-commercial use, distribution, and reproduction in any medium, provided the original work is properly cited

\section{ABSTRACT}

Background: This study aimed to find out the frequency of singleton term breech presentation and to complete the fetomaternal outcome between spontaneous vaginal and caesarean delivery. We conducted an observational prospective study to describe neonatal outcome of vagina verses cesarean delivery for term breech presentation.

Methods: The study was conducted in department of Gynae and Obs. Unit-1, LUMHS, Jamshoro from $1^{\text {st }}$ January 2011 to $31^{\text {st }}$ December 2012. All those pregnant women who were admitted in the department with singleton of breech for elective LSCS or those who were in establish labor were included after verbal informed consent.

Results: Out of 3090 Obstetrical admissions, 86 women were having breech presentation. Study divide into two groups group A - Delivered vaginally and group B - Delivered by C-section. The frequency of term breech presentation was $3 \%$ (86 out of 3090 obstetrical admissions).

Conclusions: Cesarean section, both, elective and emergency, LSCS is more safe for neonates. Maternal morbidity is comparable in both groups.

Keywords: Vaginal, Breech presentation, Comparative

\section{INTRODUCTION}

Cardiac Breech presentation is defined as a fetus in a longitudinal lie with the buttocks or feet closest to the cervix. This occurs in $3-4 \%$ of all deliveries. The percentage of breech deliveries decreases with advancing gestational age from $22 \%$ of births prior to 28 weeks' gestation to $7 \%$ of births at 32 weeks' gestation to $1-3 \%$ of births at term. ${ }^{1,2}$ Predisposing factors for breech presentation include prematurity, uterine malformations or fibroids, polyhydramnios, placenta previa, fetal abnormalities (e.g., CNS malformations, neck masses, aneuploidy), and multiple gestations. Fetal abnormalities are observed in $17 \%$ of preterm breech deliveries and in $9 \%$ of term breech deliveries.

Perinatal mortality is increased 2- to 4- fold with breech presentation, regardless of the mode of delivery. Deaths are most often associated with malformations, prematurity, and intrauterine fetal demise..$^{3-5}$ The perinatal mortality in breech delivery is 4-10 time that of vertex delivery. ${ }^{6}$ The perinatal mortality rate of breech babies delivered vaginally is three times more frequent than for babies in cephalic presentation, and is especially more common in very low birth weight infants, ${ }^{4}$ not only because of prematurity related complications. Aftercoming head entrapment in preterm babies is explained by the fact that the pre-term baby, a fetal head is usually considerably larger than the body, and the body is delivered before the cervix is fully dilated. ${ }^{7}$ These risks are especially high in footling breech presentation. ${ }^{8}$ Planned cesarean section, at least at term, reduces the risk of perinatal/neonatal mortality or serious neonatal morbidity by $67 \%$, compared to planned vaginal birth. ${ }^{9}$

This study aims to plan to observe and compare fetomaternal outcome in caesarean verses spontaneous breach delivery. 


\section{METHODS}

The study was conducted in Department of Gynecological \& Obstetrics Unit-1 Liaquat University of Medical \& Health Sciences Jamshoro \& Hyderabad from $1^{\text {st }}$ January 2011 to $31^{\text {st }}$ December 2012. 100 patients were included in this study sampling technique used non probability propulsive convenient type. All those pregnant women who were admitted in the department with singleton of breech for elective LSCS or those who were in establish labor were included after verbal informed consent.

Data was collected on a prepared proforma covering the relevant information's required for the study. It was pre tested prior to the actual study period. A detailed orientation of the study and enrollment system was given to all concerned doctor colleagues and ward in-charge, nursing staff.

All women with preterm gestation, multiple pregnancy and previous LSCS were excluded from the study. Required information was collected on predesigned proforma including demographic, maternal and fetal complications. Total number of obstetric admissions was 3090 , women with breech presentation were 86 and Incidence was $2.8 \%$. A comparative study which was divided into two groups, "A" - Delivered vaginally and "B" - Delivered by C-section. Duration and progress of labor were monitor in photograph fetal monitor by intermittent (CTG) has been done.

Apgar score of baby was noted, time of delivery (from delivery of the body up to the delivery of head) was noted, and also complications were noted during delivery like birth aspaxia and birth trauma. Data was compiled on a computer on a SPSS (Statistical Package for Social Sciences) for Windows version 10.0 program and analyzed.

\section{RESULTS}

Out of 3090 Obstetrical admissions, 86 women were having breech presentation. The frequency of term breech presentation was $3 \%$ (86 out of 3090 Obstetrical admissions). About $75 \%$ of the women were young (2030years) in both groups. Primigravidas were more in cesarean group, while multigravida predominates in vaginal delivery group. The frequency of maternal complications was insignificant except anemia which was more in cesarean group. Prenatal mortality rate was significantly high in vaginally delivered breech $22 \%$ as compared to breech delivered by LSCS $5 \%$.

Table 1: Obstetrical admissions.

\begin{tabular}{|lll|}
\hline $\begin{array}{l}\text { Total obstetric } \\
\text { admissions }\end{array}$ & $\begin{array}{l}\text { Women with breech } \\
\text { presentation }\end{array}$ & Incidence \\
\hline 3090 & 86 & $2.8 \%$ \\
\hline
\end{tabular}

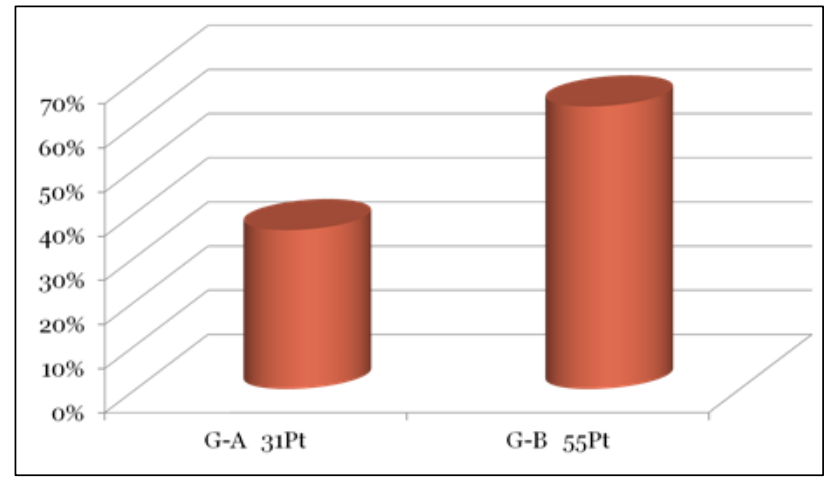

Figure 1: Vaginal vs. cesarean breech delivery.

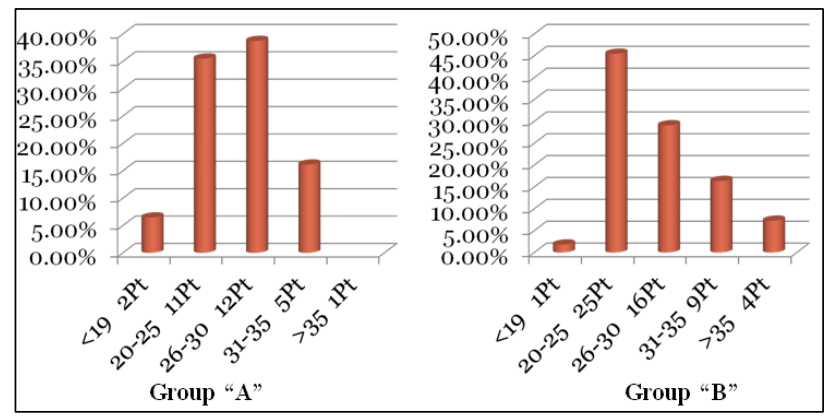

Figure 2: Age distribution in group "A" and group " $B$ " most patients with breech presentation were in their twenties with the youngest being 17 years old and the eldest more than 35 years old.

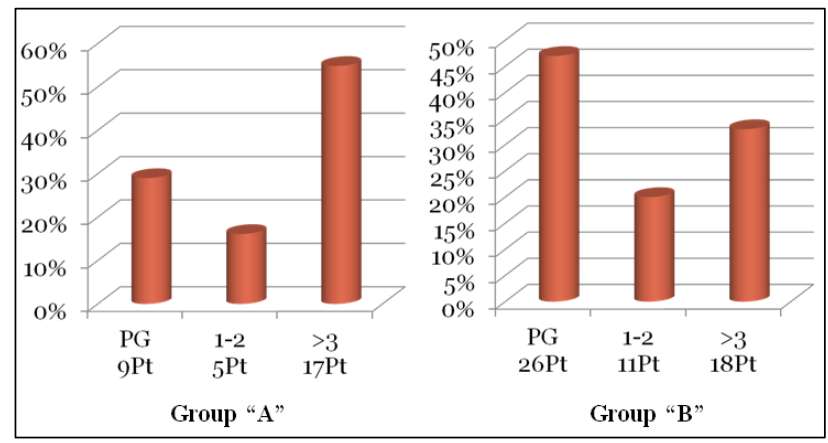

Figure 3: Parity distribution in group "A" and group "B" majority of the patients with breech presentation.

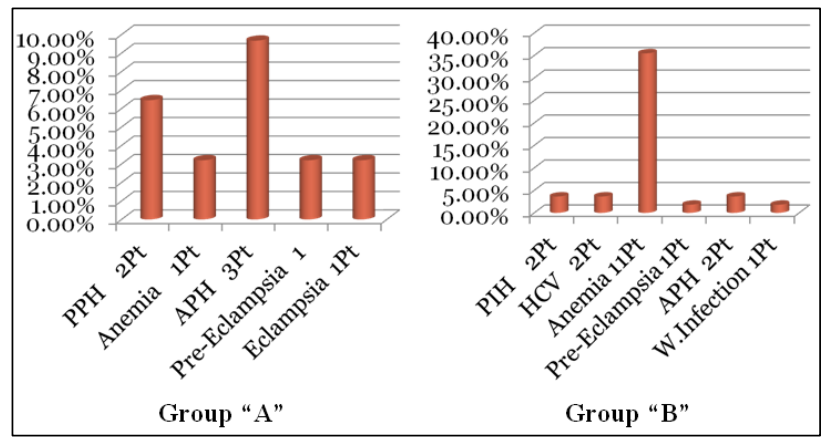

Figure 4: Maternal complications in group " $\mathrm{A}$ " and group "B". 


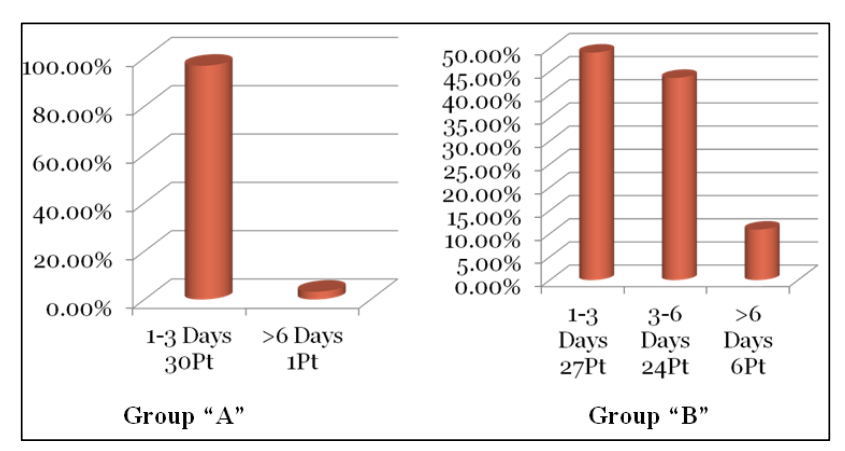

Figure 5: Duration of hospital stay in group " $A$ " and group "B".

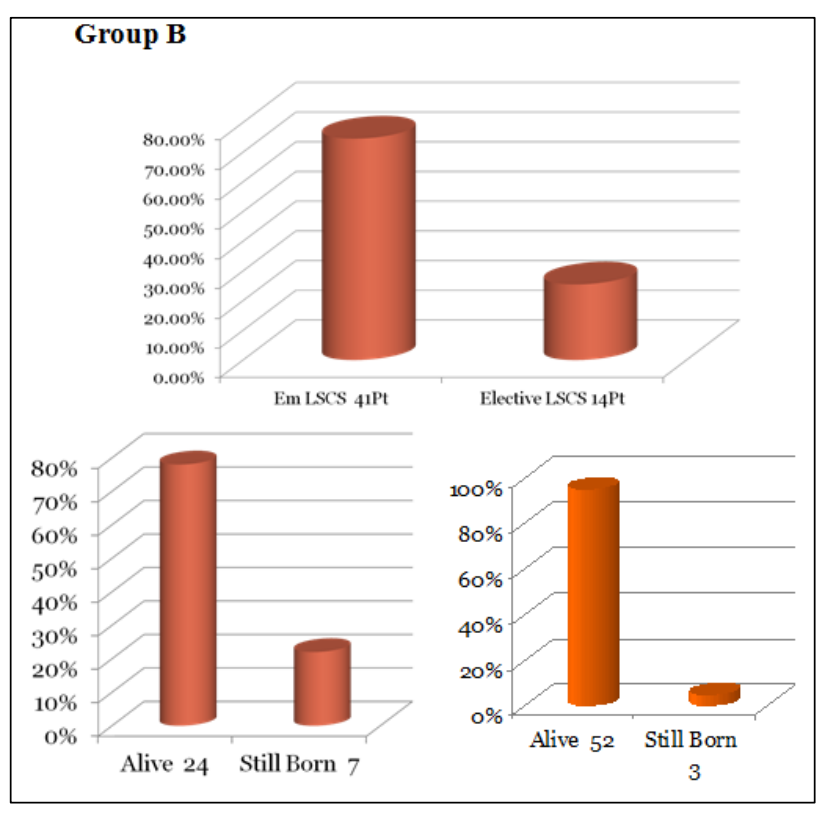

Figure 6: Fetal Outcome in group "A" and group "B".

\section{DISCUSSION}

Vaginal breech birth can be associated with a higher risk of perinatal mortality and short-term neonatal morbidity than elective caesarean section and our study corresponds with study by Hofmeyr M, Hannah M et al. (2003). ${ }^{10}$ However careful case selection and labour management in a modern obstetrical setting may achieve a level of safety similar to elective caesarean section. With careful case selection and labour management, perinatal mortality occurs in approximately 2 per 1000 births and serious short-term neonatal morbidity in approximately $2 \%$ of breech infants. ${ }^{11}$ Many recent retrospective and prospective reports of vaginal breech delivery that follow specific protocols have noted excellent neonatal outcomes. ${ }^{10}$ Our series had a neonatal mortality rate of $8.8 \%$ Long-term neurological infant outcomes do not differ by planned mode of delivery even in the presence of serious short-term neonatal morbidity. Planned vaginal delivery of a term singleton breech fetus may be reasonable under hospital-specific protocol guidelines for both eligibility and labor management. Before a vaginal breech delivery is planned, women should be informed that the risk of perinatal or neonatal mortality or shortterm serious neonatal morbidity may be higher than if a cesarean delivery is planned, and the patient's informed consent should be documented. ${ }^{12}$

The incidence of breech presentation at term in this study was $2.4 \%$. This corroborates with the figures reported in other studies. ${ }^{13,14}$ The management of breech presentation at term has remained controversial and some authors recommend a policy of elective cesarean section for all term breech fetuses. ${ }^{15,16}$ This has led to an increased use of cesarean section. Recently, a number of studies have reported vaginal delivery of the term breech as an acceptable obstetric choice in selected cases. ${ }^{17,18}$

Breech presentation creates a mechanical problem in the delivery of fetus. This malpresentation is associated with increased frequency of perinatal mortality and morbidity due to prematurity, congenital anomalies and birth trauma or asphyxia. Some clinicians have recommended a policy of caesarean section for breech presentation at term based on results of nonrandomized studies, anecdotal experiences, and medico -legal concerns. ${ }^{19}$ Others, who were experienced with vaginal breech delivery, have continued to recommend planned vaginal birth for selected cases, with the view that vaginal birth would be associated with lower morbidity for the mother, require fewer health-care resources, and would be less costly. ${ }^{20} \mathrm{It}$ was reported that after the results of the term breech trial that there was an increase in elective caesarean section from $25 \%$ in to $64 \%$. However, this rise in caesarean section also resulted in four maternal deaths that may have been avoidable. Furthermore, in the future, nineteen perinatal deaths as a result of the uterine scar and 140 women with potentially life threatening complications from that uterine scar during their future pregnancies can be expected. Information to the patient should take into account not only the short-term benefits but also the higher long-term risks. Vaginal delivery following strict selection is now preferred. ${ }^{21}$ The incidence of breech presentation was $3.6 \%$ in this study which is in accordance with the reported data of $3-5.3 \%$ in local literature. $^{22-24}$ The frequency of breech presentation increases with age and parity. The age range in which multiparous women are concentrated in our community could be attributed to early marriages and lack of family planning. Various studies suggest that vaginal breech delivery still remains a viable option in selected patients. ${ }^{25,26}$ Selective vaginal breech deliveries may be safely undertaken in units having a tradition of vaginal breech deliveries. Maternal morbidity in breech vaginal delivery is low and it is significantly higher in the caesarean section. ${ }^{27,28}$

The result of this study seems to favor cesarean delivery as a safer mode of delivery for term breech presentations in comparison to vaginal deliveries, in terms of immediate neonatal outcomes. This probably reflects fetal hypoxia and acidemia occurring as a result of prolonged umbilical cord compression during vaginal delivery. The probability that vaginal breech birth can be 
associated with a higher risk of perinatal mortality and short-term neonatal morbidity than elective caesarean section should be kept in mind. However careful case selection and labour management in a modern obstetrical setting may achieve a level of safety similar to elective caesarean section. However a larger scale study is recommended to study long term neonatal and maternal outcomes before advocating routine cesarean section in all breech presentation.

It was concluded that cesarean section, both, elective and emergency, is found to be safer for neonates as compared to vaginal delivery in case of term breech. However in clinical experience many breaches have been delivered vaginally without any adverse outcome.

\section{Recommendations}

Women should be informed of the benefits and risks, both for the current and for future pregnancies, of planned cesarean section versus planned vaginal delivery for breech presentation. The planned cesarean section carries a reduced perinatal mortality and early neonatal morbidity for babies with a breech presentation at term compared with planned vaginal birth. There is no evidence that the long term health of babies with a breech presentation at term is influenced by how the baby is born.

Funding: No funding sources

Conflict of interest: None declared

Ethical approval: The study was approved by the institutional ethics committee

\section{REFERENCES}

1. Pritchard JA, Mac Donald PC. Dystocia caused by abnormal - lities in presentation, or development of the fetus. William olostdric. 24th ed. Norwalk, CT: Appleton-century-crofts; 2001: 423-439.

2. Klufio CA, Amoa AB. Breech presentation and delivery. PNG Med J. 1991;34:289-95.

3. Braun F. H. T., Jones K. L., Smith D. W. Breech presentation was an indication of fetal abnormality. $\mathrm{J}$ Paed. 1975;86:419.

4. Apeawusu B. Amoa, Mathias Sapuri. Perinatal out come and associated factors of persistent breech presentation at the port Mores by General Hospital, Papua new Guinea. PNG Med J. 2001 Mar-Jun;44(12):48-56.

5. Sanders W. B. High risk pregnancy management options. In: DK James, PJ Steer, CP Weiner, B Gonik, eds. Chapter 58. 2nd ed. London, England: W. B. Saunders; 1999: 1025.

6. Gimovsky ML, Paul Rh. Singleton breech presentation in labour: experience in 1980. AMJ obstet Gynecol. 1982;143:733-9.

7. Dewhurst's Chapter 23. Keith Edmonds, eds. Text book of obstetrics and Gynecology for postgraduate study. 6th ed. London, England: Blak well science LTD; 1999: 277.
8. Anderew S. Oco, Stephanie D. Silverman. External cephalic version. American Family Physician. 1998 Sep;58(3):731-8.

9. Lau TK, Lokw, Rogers M. pregnancy outcome after successful external cephalic version for breech presentation at term. Am J Abstet Gynecol. 1997; 176:218-23.

10. Hofmeyr GJ, Hannah M, Lawrie TA. Planned caesarean section for term breech delivery. Cochrane Database of Systematic Reviews. 2003;2:CD000166.

11. Igwegbe A. O., Monago E. N., Ugboaja J. O. Caesareanvs vaginal delivery for term breech presentation: A comparative analysis. Afr J Biomed Res. 2010 January;13(1):15-8.

12. ACOG Committee on Obstetric Practice. ACOG Committee opinion, number 340. Mode of term singleton breech delivery. Obstet Gynecol. 2006 Jul;108(1):235-7.

13. Stiff E, Friedman S, Mashiach S et al. Maternal and neonatal outcome of 946 singleton breech deliveries. Am J Obstet Gynecol. 1996;175:18-23.

14. Wright RC. Reduction of perinatal mortality and morbidity in breech delivery through routine use of cesarean section. Obstet Gynecol. 1959;14:758-63.

15. Collea JV, Chein C, Quilligan EJ. The randomized management of term frank breech presentation at term: A study of 208 cases. Am J Obstet Gynecol. 1980;137:235-49.

16. Rosen M, Chik L. The effect of delivery route on outcome in breech presentation. Am J Obstet Gynecol. 1984;148:909-14.

17. Hickok DE, Gordon DC, Milberg JA et al. The frequency of breech presentation by gestational age at birth: a large population-based study. Am J Obstet Gynecol. 1992;166:851-52.

18. Weiner CP. Vaginal breech delivery in the 1990s. Clin Obstet Gynecol. 1992;35:559-61.

19. Nahid F. Outcome of singleton term breech cases in the pretext of mode of delivery. J Pak Med Assoc. 2000;50:81-5.

20. Hannah ME, Hannah WJ, Hewson SA, Hodnett ED, Saigal S, Willan AR. Planned caesarean section versus planned vaginal birth for breech presentation at term: a randomised multicenter trial. Term Breech Trial Collaborative Group. Lancet. 2000;356:137583.

21. Irion $\mathrm{O}$, Hirsbrunner Almagbaly $\mathrm{P}$, Morabia $\mathrm{A}$. Planned vaginal delivery versus elective caesarean section: a study of 705 singleton term breech presentations. Br J Obstet Gynaecol. 1998;105:7107.

22. Verhoeven AT, de Leeuw JP, Bruinse HW. Breech presentation at term: elective caesarean section is the wrong choice as a standard treatment because of too high risks for the mother and her future children. Ned Tijdschr Geneeskd. 2005;149:2207-10.

23. Rauf B, Ayub T. Maternal and perinatal outcome in term singleton breech presentation. J Postgrad Med Inst. 2004;18:373-9. 
24. Zafar F, Imtiaz S, Hussain U, Nausheen F. Incidence, mode of delivery and Apgar score in breech presentation. Ann King Edward Med Coll. 2000;2:179-82.

25. Doyle NM, Riggs JW, Ramin SM, Sosa MA, Gilstrap LC 3rd. Outcomes of term vaginal breech delivery. Am J Perinatol. 2005;22:325-8.

26. Hellsten $C$, Lindqvist $\mathrm{PG}$, Olofsson $\mathrm{P}$. Vaginal breech delivery: is it still an option? Eur J Obstet Gynecol Reprod Biol. 2003;111:122-8.

27. Molkenboer JF, Debie S, Roumen FJ, Smits LJ, Nijhuis JG. Maternal health outcomes two years after term breech delivery. J Matern Fetal Neonatal Med. 2007;20:319-24.

28. Bashir R, Khattak K, Anwar A. Planned vaginal delivery versus elective lower segment caesarean section for breech presentation at term. J Ayub Med Coll. 2000;12:3-5.

DOI: $10.5455 / 2320-1770 . i j r \operatorname{cog} 20140328$

Cite this article as: Dars S, Malik S, Bhurgri A. Is breech still being delivered vaginally? A

comparative study. Int J Reprod Contracept Obstet Gynecol 2014;3:144-8. 